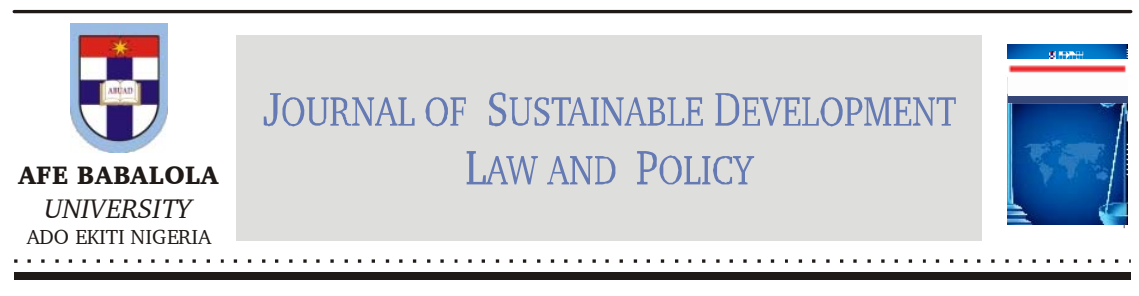

\title{
SUSTAINABLE DEVELOPMENT GOALS, EXTRACTIVES INDUSTRIES AND THE ENERGY NEXUS - INSIGHTS IN THE MENA REGION
}

\author{
John Kilani*
}

\begin{abstract}
Sustainable development is undoubtedly one of the biggest challenges the world continues to face today. We live in a world where more than 800 million people still live in extreme poverty; one out of nine people are starving; 2.5 billion lack access to clean water; and 1.3 billion people have no access to modern electricity. It is against this backdrop that the world leaders in September 2015 adopted the 2030 Agenda for Sustainable Development, enshrining the 17 UN Sustainable Development Goals (SDGs) - a new, universal set of goals, targets and indicators that all UN Member States are expected to use for framing their sustainable development agendas and policies until 2030. This article seizes the opportunity to engage in the ongoing discourse on the contributions from major sectors to the realization of the SDGs, particularly in the face of growing world population. The purpose of the article is to explore the role of the energy sector in the implementation of sustainable development agendas, particularly in the MENA region. The article finds that the region's diverse circumstances and substantial petroleum and natural gas reserves make it an ideal region for typifying the central role of energy in today's world. The article explores, under five themes, some pertinent issues relating to the UNSDGs and their connectivity to energy, drawing illustrative examples from four countries - one small resourcerich country (Qatar), one relatively large resource-rich country (Saudi Arabia), the largest country from North Africa (Egypt), and a country
\end{abstract}

* Director of Sustainable Development, The Abdullah Bin Hamad Al-Attiyah International Foundation for Energy and Sustainable Development, Doha, Qatar. 
grappling with the challenges of reconstruction after years of strive and instability (Iraq). The article highlights that some of the countries are successfully unlocking the benefits of economic growth, through the development of their natural resources. It concludes that, through concerted efforts to address some challenges, extractive sector operations can play significant roles in advancing the SDGs in the entire region.

Keywords: Sustainable Development; UNSDGs; Energy; MENA Region.

DOI: https://dx.doi.org/10.4314/jsdlp.v11i2.9

\section{INTRODUCTION: SUSTAINABILITY IN THE CONTEXT OF THE EXTRACTIVE INDUSTRY}

The global community has witnessed an unprecedented rise in attention given to sustainable development over the past few decades, during which time it has evolved through several phases. ${ }^{1}$ In this ever-growing discourse on sustainable development, the sustainability of industry sectors that are founded on the extraction of finite, non-renewable natural resources, such as oil and gas, remains a major topic of debate. The most enduring and universally accepted definition of sustainable development - the Brundtland definition - remains at the centre of the debate, i.e. "development that meets the needs of the present without compromising the ability of future generations to meet their own needs."2 This definition provides a good reference point for the historical evolution of sustainable development. There is broad agreement in the international community that the definition of sustainable development embraces the Brundtland interpretation that the manner of our growth and prosperity today should not compromise the prospects of future generations to do the same.

Three pillars of sustainable development are inherent in the Brundtland definition - economic development, social progress, and environmental management (and conservation) - the so-called three overlapping circles. Over time, and through the multilateral processes of the UN Commission for Sustainable Development (UNCSD), a fourth

1 Audrey Haylins, "The 2030 Development Agenda: Energy Access a Keystone" OFID Pamphlet Series 40, OPEC Fund for International Development (OFID).

2 The United Nations World Commission on Environment and Development Report, Our Common Future (OUP 1987) 1-10 (the Brundtland Report). 
dimension (governance) which transcends all the other three pillars, became commonly identifiable. The 2030 Agenda for Sustainable Development for many nations are usually framed around these four pillars.

The evolutionary process of sustainable development is depicted by the moving shift in the global focus on each of the three pillars and their relation to each other. Four distinctive phases could be recognized in this evolutionary process. ${ }^{3}$ At each evolving phase, the definition, nature and scope of the concept widens significantly, raising the stakes and spectre of international community's interest and engagement in the sustainable development debate.

Pre-Brundtland Phase - The pre-Brundtland definition was characterized with predominant focus on economic development, without much attention paid to environmental conservation. Environmental awareness was generally poor.

Brundtland Commission - The growing environmental campaign in the late 70s and early 80s led to the establishment of the Brundtland Commission in December 1983, by the United Nations General Assembly. The Commission, chaired by Ms Gro Harlem Brundtland, the Prime Minister of Norway at the time, developed what is widely referred to as the Brundtland definition of sustainable development. The definition was contained in a unanimous report, Our Common Future, produced by

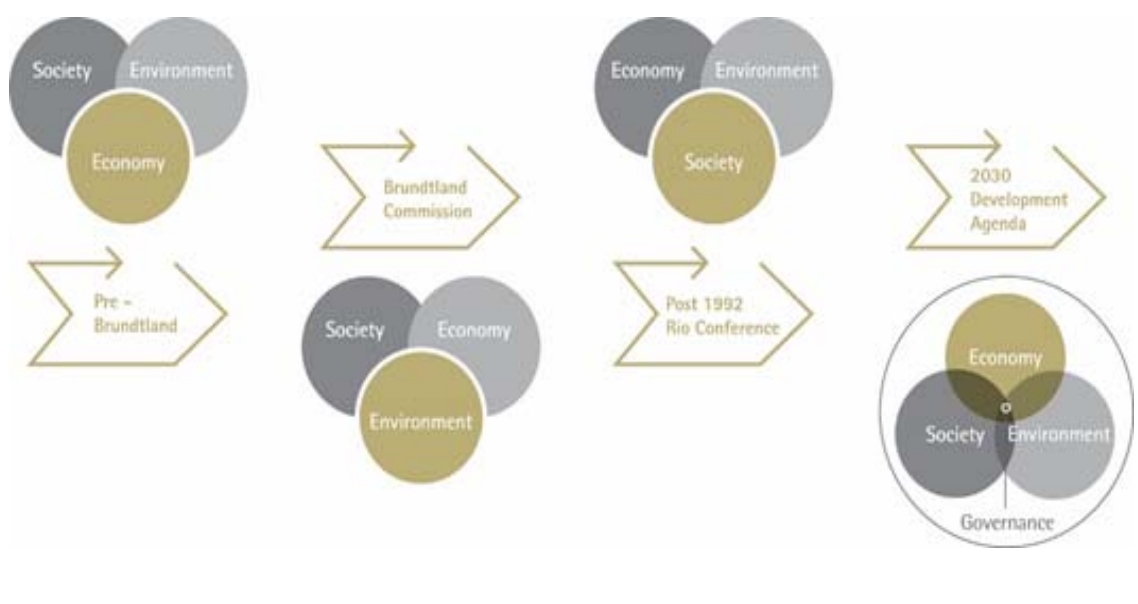

3 Damilola Olawuyi, Principles of Nigerian Environmental Law (Afe Babalola University Press, 2015), 63-65. 
the 22-member Commission, and presented to the UN General Assembly in October 1987 (UN, 1987). The Brundtland definition inadvertently shifted the focus of sustainable development to ecology and biodiversity. Post 1992 Rio Conference - The United Nations Conference on Environment and Development (UNCED) - the Earth Summit - which took place in Rio de Janeiro in June 1992, was a milestone event that shaped the framing of the global Sustainable Development Agenda. Growing global debate on sustainable development since the summit shifted the world focus to a more anthropological perspective where increasing emphasis is placed on human condition and quality of life. The Rio Declaration on Environment and Development and the Agenda 21 document were adopted by world leaders at the Earth Summit, for all nations to use in defining their work programme, for the 21st century in all areas of sustainable development. ${ }^{4}$

2030 Development Agenda - In 2001, governments adopted the Millennium Development Goals (MDGs), and in 2015 replaced them with the Sustainable Development Goals (SDGs). The SDGs are a new, universal set of goals, targets and indicators that all UN Member States are expected to use for framing their sustainable development agendas and policies for 15 years, post 2015. The MDGs and SDGs ushered in an era where environmental, social and economic considerations, in perfect harmony with transparent governance, has become the hallmark of sustainable development best practice, among companies of all shapes and sizes worldwide. The adoption of the SDGs is increasingly recognized by all major stakeholders in the global sustainable development debate as representing a pragmatic approach. The next section examines the connections between the SDGs and the energy sector. It evaluates why and how the energy sector will have crucial roles to play in the advancement of the SDGs.

\section{CONNECTIONS BETWEEN ENERGY AND SUSTAINABLE DEVELOPMENT IN THE MENA REGION}

The 17 UN SDGs provide a comprehensive coverage of the elements of human development, incorporating all aspects of environmental, social and economic activities. While the 17 goals are interlinked and

4 The Brundtland Report (n.2). See also Olawuyi (n.3). 
interconnected, they can be categorized into the following four broad clusters, together with the last standalone goal on partnership, as a fifth cluster:

1. Goals addressing immediate human needs: Poverty reduction, ending hunger, good health, quality education, and access to clean water and sanitation;

2. Goals addressing fundamental environmental issues: Climate change, life below water, and life on land;

3. Goals relating to social-economic development: Access to energy (including renewables), economic growth and decent work, industry and infrastructure, sustainable cities, and responsible consumption and production;

4. Goals embodying significant UN principles: Gender equality, reduced inequalities, peace and justice; and

5. The standalone Goal 17 on global partnership for sustainable development. ${ }^{5}$

The Middle East and North Africa (MENA) is a region encompassing approximately 22 countries (Algeria, Bahrain, Djibouti, Egypt, Iran, Iraq, Israel, Jordan, Kuwait, Lebanon, Libya, Malta, Morocco, Oman, Qatar, Saudi Arabia, Syria, Tunisia, United Arab Emirates, Palestine, and Yemen, with Ethiopia and Sudan sometimes included). ${ }^{6}$ The MENA region accounts for approximately 6 per cent of the world's population, 60 per cent of the world's oil reserves and 45 per cent of the world's natural gas reserves. ${ }^{7}$ Notwithstanding the relatively small population, the region's diverse circumstances and substantial petroleum and natural gas reserves, make it an ideal region for typifying the central role of energy in today's world.

Many countries in the MENA Region, consistent with the global approach to the implementation of the UNSDGs, have clearly articulated

5 See UNSDG Index and Dashboard, http://www.sdgindex.org/assets/files/2017/ 2017-SDG-Index-and-Dashboards-Report - full.pdf. See also https:// sustainabledevelopment.un.org/vnrs/

6 See World Bank, Middle East and North Africa, < https://data.worldbank.org/ region/middle-east-and-north-africa $>$ accessed 3 October 2018.

7 BP, Energy Outlook, BP Statistical Review of World Energy (67th Edition, BP, June 2018) 12, <https://www.bp.com/content/dam/bp/business-sites/en/global/ corporate/pdfs/energy-economics/statistical-review/bp-stats-review-2018-fullreport.pdf $>$ accessed 27 June 2019 (hereafter BP, Statistical Review of World Energy). 
their sustainable development priorities in what is commonly referred to as Vision 2030. In this section of the article, the pertinent issues in some of the Visions and their connectivity to energy are considered under five themes, drawn from the above five clusters. Illustrative examples are drawn from four countries, in particular - one small resource-rich country (Qatar), one relatively large resource-rich country (Saudi Arabia), the largest country from North Africa (Egypt), and a country grappling with the challenges of reconstruction after years of strive and instability (Iraq).

\subsection{Theme One - Energy and Human Welfare (Goals 1, 2, 3, 4, \& 6)}

First and foremost, all households require a minimum amount of energy to meet their basic subsistence needs, such as cooking, lighting and heating. ${ }^{8}$ In addition, more and modern commercial energy is needed to meet other welfare-enhancing services and amenities that are essential for improved welfare and quality of life. The human pillar featured prominently in the sustainable development programmes of all countries in the MENA region, as highlighted by the following four examples (Voluntary National Reviews - UN Sustainable Development Knowledge Platform).

The Qatar National Vision 2030, with its four pillars (human, social, economic and environmental development), aims at transforming Qatar into an advanced country, capable of achieving sustainable development and ensuring the continuation of decent living standards for its people, generation after generation, by seeking to develop a diversified economy coupled with diminishing dependence on hydrocarbons, where investment is moving towards a knowledge-based economy and the private sector is growing in importance. ${ }^{9}$ Similarly, the core objective of Iraq Vision 2030 is to achieve sustainable improvement in the quality of life, ensure sustainable production and consumption patterns, reduce the adverse effect of pollution and climate change and enhance the protection of biodiversity. One of the five cardinal goals set by Iraq in its Vision 2030

8 Ranjit Lamech \& Kyran O'Sullivan, Energy in World Bank Publication: A Sourcebook for Poverty Reduction Strategies (Macroeconomic sectoral approaches, World Bank, 2002).

9 Government of Qatar, General Secretariat for Development Planning, Qatar National Vision 2030 (General Secretariat for Development Planning (GSDP) 2008); GSDP, Qatar National Development Strategy 2011- 2016 (GSDP 2011). 
is to develop and enhance the spirit, mind and health of its people; leading to building generations that are capable of innovation, creativity and achievement. The poverty rate in Iraq was 22.9 per cent in 2007. This was reduced to 18.9 per cent in 2012, but the double crisis with the resultant drop in oil production and sharp increase in the cost of energy, led to a rise in poverty in 2014 to about 22.5 per cent. This rate fell in 2018 to 20.5 per cent as a result of improved economic and security conditions. ${ }^{10}$ The Sustainable Development Strategy of Egypt (SDS) Egypt Vision 2030 - provides the national framework that guides and sets policies and programmes for all stakeholders, including the private sector, civil society and international organizations, working together to achieve the SDGs, as well as other national objectives. The SDS acts as the governing framework for all development programmes and projects to be implemented until 2030. The programmes include measures to address the problem of hunger; provide good healthcare; and reduce the impact of poverty on the quality of life, by addressing the critical social problem of the growing proportion of the population living below the international poverty line (26.3 per cent in $2012 / 2013$ and 27.8 per cent in 2015). ${ }^{11}$ The Saudi Vision 2030 rests on three thematic pillars - a vibrant society, a thriving economy and an ambitious nation - and provides the foundations underpinning the integration of Sustainable Development Goals into the national planning process. The judicious use its oil revenue is at the heart of the dramatic and comprehensive transformation the Kingdom of Saudi Arabia is experiencing. In 2015 the Kingdom's efforts in the area of social development included total expenditure for social insurance pensions (US $\$ 4.53$ billion); total annual assistance provided to charitable societies (US\$ 120 million); and total annual assistance to cooperative societies (US\$ 26.67 million). The King Salman Humanitarian Aid and Relief Centre provided assistance in excess of US $\$ 262$ million to secure food in various parts of the world during the period 2015-2018. In 2018, budget allocations for the health services and social development sectors amounted to around US\$ 39.2 billion. This ensured that Saudi Arabia's health sector made significant progress

10 Republic of Iraq, Ministry of Planning, National Development Plans, Iraq Vision 2030 https://planipolis.iiep.unesco.org/sites/planipolis/files/ressources/ iraq_vision_2030_en.pdf

11 Government of Egypt, Egypt Vision 2030, < https://www.greengrowth knowledge.org/sites/default/files/downloads/policy-database/Egypt\%20 Vision\%202030\%20\%28English\%29.pdf> 
overall, ranking 26th out of 190 countries, in a survey by the World Health Organization in 2017. ${ }^{12}$

The exploitation and prudent management of natural resources such as oil and gas are providing a significant revenue source for governments in the MENA region, and offering opportunities for poverty reduction. For some countries, such as Qatar, the scale of these potential revenues is extremely large relative to the population and the size of the local economy, thereby forming a significant boost to development. Conversely, those countries that cannot develop their local resources, due to some socio-economic and political challenges, are not able to generate substantial fiscal revenues needed for public spending in support of poverty reduction. ${ }^{13}$

\subsection{Theme Two - Energy and Environmental Concerns (Goals 13, 14, \& 15)}

The negative impacts of energy development, production and utilization on air, land and human health constitute the major drawback to the energy industry's contribution to sustainable development. ${ }^{14}$ These impacts on biodiversity and the ecosystem, coupled with the finite nature of non-renewable natural resources, provide credence to those who argue that the extractive industry should only get a license to operate if they are applying best practices to protect the environment. There is also increasing advocacy that other interests, such as protection of sensitive environments, national parks or indigenous people, should have priority over natural resource extraction.

The prominence of the environmental pillar in the sustainable development programmes of most countries of the MENA region, signifies a recognition of the daunting challenges that the extractive industry, in resource-rich countries faces. While some progress is visible, there is still an urgent need for increased actions and ambitions in this pillar (Voluntary National Reviews - UN Sustainable Development Knowledge Platform). In Qatar, there is a commitment to continue to explore

12 Saudi Arabia National Vision 2030, <http:// vision2030.gov.sa/en>

13 See Damilola Olawuyi, "Advancing Innovations in Renewable Energy Technologies as Alternatives to Fossil Fuel Use in the Middle East: Trends, Limitations, and Ways Forward" in Donald Zillman, Martha Roggenkamp, LeRoy Paddock and Lee Godden, (eds.) Innovation in Energy Law and Technology: Dynamic Solutions for Energy Transitions (Oxford University Press, 2018), 354370.

14 World Health Organization (WHO), 2015. World Health Statistics 2015. 
sustainable solutions, such as seeking alternative sources of energy, curbing excessive consumption of resources, reducing $\mathrm{CO}_{2}$ emissions, enhancing efforts to achieve water and food security and expanding recycling efforts. There is also a recognition for the need for a paradigm shift involving a holistic approach that embraces the concept of the circular economy and a robust framework for sustainable growth. ${ }^{15}$ The Iraq Vision 2030 aims at building an "empowered people in a safe country, a unified society with diversified economy, sustainable environment, justice, and good governance". Ensuring sustainable production and consumption patterns, reducing the adverse effect of pollution and climate change and enhancing the protection of biodiversity are some of the core objectives of Iraq Vision 2030. ${ }^{16}$ Similarly, as part of the implementation of its Sustainable Development Strategy (SDS) - Egypt Vision 2030, Egypt established several institutions and mechanisms, including the National Council on Climate Change, to drive its efforts to fight climate change. With approximately 3,200 km of coastline across both the Mediterranean and the Red Seas, Egypt is home to a rich diversity of marine life and coastal geography that plays a pivotal role in attracting tourism. An Integrated Coastal Zone Management (ICZM) was established in an effort to conserve these valuable natural resources and to protect and effectively manage the country's marine and coastal areas. In addition to several environmentally friendly national strategies, Egypt endorses regional and international conventions, including the 1992 Convention on Biological Diversity. To date, there are 30 natural protectorates in Egypt, covering approximately $140,000 \mathrm{~km}^{2}$ (nearly 13.9 per cent of the total area). ${ }^{17}$ The process of waste management, recycling, re-use, energy recovery and circular economy are important elements of the Kingdom of Saudi Arabia's approach to conservation of natural resources, creation of job opportunities, reduction of greenhouse gas emissions from landfills and conversion of waste to energy. ${ }^{18}$

The energy industry, in particular oil and gas, needs to be environmentally responsible, even more than most other industries, because of the high visibility and potentially far reaching consequences of the environmental impacts associated with the sector. The more significant progress is made, in good operational practices and advances

15 See Olawuyi (n. 12).

16 Republic of Iraq (n.9).

17 Government of Egypt (n. 10).

18 Saudi Arabia National Vision 2030 (n.11). 
in responsible environmental management, the greater the recognition and basis for acceptance of the contribution the sector can make to sustainable development.

\subsection{Theme Three - Energy and Socio-Economic Development (Goals 7, 8, 9, 11, 12)}

Despite several attempts to decouple economic growth and energy consumption, the two seem to be linked in a feedback loop: increased energy access fosters income growth, while energy use tends to increase with income. In developing countries, in particular, energy is regarded as a resource to fuel economic growth. ${ }^{19}$

One recurring theme, in the sustainable development plans of countries of the MENA region, irrespective of the level of endowment with natural resources, is the need to explore or develop additional sources of energy in their energy mix. ${ }^{20}$ For example, Qatar has worked to increase the thermal efficiency in energy production, embark on extensive awareness campaign about efficient energy consumption, and increase the share of renewables in total country's energy needs. Iraq recognizes that heavy reliance on oil is making its economy highly sensitive to international circumstances, which in turn is affecting its ability to mobilize enough financial resources for SDG-related investments. Therefore, prioritizing economic diversification is considered key to the realization of Iraq Vision 2030. Egypt's Integrated Energy Strategy outlines the details of how Egypt will produce, utilize and conserve energy through to 2035. The strategy is geared towards transforming the country's energy sector into one that plays an important role in the economy while ensuring a reliable, efficient and eco-friendly usage of domestic resources. The country's heavy dependency on fossil fuels (more than 90 per cent of its power supply) being a major focus, with the determination to capitalize on the abundance of land, a sunny climate, and high wind speeds that make the country a prime location for generating renewable energy. Egypt aims to generate 20 per cent of its power from renewable sources by 2022 and 37 per cent by 2035. Similarly, the Kingdom of Saudi Arabia has paid great attention to the development of renewable energy, particularly solar, wind and nuclear power, launching several programmes, projects and initiatives in this regard. Under the Vision 2030 and related National

19 Audrey (n.1).

20 Olawuyi (n. 12). 
Transformation Programme, Saudi Arabia has a target to produce 4 per cent of its total energy from renewable sources by 2020, and 10 per cent by 2030 .

The economic impacts of energy development include higher government revenues and job creation, and the energy sector can also contribute to broader regional prosperity. ${ }^{21}$ Several resource-rich countries in the MENA region are massively diversifying the local industrial base and leveraging industry clusters to spur innovation. Through clusterbased development, economically successful countries within the region have knitted together companies, teaching and research institutions and different levels of government to create uniquely competitive industries. ${ }^{22}$

\subsection{Theme Four - Energy and Ethical Issues \& Principles (Goals 5, 10 \& 16)}

By 2015 the world had overcome some of what seemed, 25 years ago, to be its most daunting challenges. Yet even with this commendable progress, the world still faces many complex development challenges, such as lingering deprivations and deepening inequalities. ${ }^{23}$

Basic human deprivations are common among various groups. Women and girls, ethnic minorities, indigenous peoples, persons with disabilities, migrants - all experience deprivations in the basic dimensions of human development. ${ }^{24}$ Globally, women make up only 26.7 per cent of all oil and gas industry professional workforce, compared to about 59.8 per cent in the healthcare sector, and 30.6 per cent in technology companies. ${ }^{25}$ The situation with the representation of women at the board level is even bleaker.

In Qatar, the number of women in public and private sector leadership positions, increased by 30 per cent compared to $2008 .{ }^{26}$ Reviews of

21 Andrew Bauer, et al, Natural Resources Revenue Sharing (The Natural Resource Governance Institute, 2016).

22 WEF and IHS CERA, Energy for Economic Growth - Energy Vision Update 2012, (World Economic Forum, 2012).

23 United Nations Development Programme (UNDP), Human Development Report 2016 - Human Development for Everyone (New York, UNDP, 2016).

24 World Bank Group, 2016. Global Monitoring Report 2015/2016 - Development Goals in an Era of Demographic Change. Washington DC, World Bank Group.

25 UNDP (n.20).

26 Planning and Statistics Authority of Qatar, Woman and Man In the State of Qatar: A Statistical Portrait 2018 https://www.psa.gov.qa/en/statistics/ Statistical\%20Releases/Social/GenrealSocialStatistics/MenWomenProfile/ 2018/Woman_Man_2018_EN.pdf 
legislations have been conducted, through legal committees or special events, to remove all identified obstacles impeding women. In Saudi Arabia, there has been a noteworthy progress in the rise of women's participation in the labour market from 12 per cent in 2009 to 18 per cent in 2017. ${ }^{27}$ Saudi Vision 2030 aims to raise this share to 25 per cent by 2020 . In Iraq, the constitution placed emphasis on eliminating discrimination against women and promoting gender equality. Despite special attention on the issue of violence against women, in its national development plans, cases of several forms of violence against girls and women both inside and outside the family are prevalent and regularly reported. ${ }^{28}$ The country still faces serious barriers to empowerment of women in the business area, senior management positions, and in public and private institutions. Egypt's National Strategy for Women Empowerment has four pillars - political empowerment and leadership, economic empowerment, social empowerment, and protection. Specific targets, to be achieved by 2030, are set under each pillar, with quantitative indicators for monitoring the progress of implementation. Although, Egypt had witnessed high economic growth rates before the uprising in 2011, there was widespread inequality in the enjoyment of the benefits of economic development. The fifth pillar of Egypt's sustainable development strategy seeks to put the constitutional articles on social justice and equality into action. It envisages Egypt in 2030 as characterized by equal economic, social, and political rights and opportunities. ${ }^{29}$

With an increasing spotlight on the impacts of resource explorations on communities, it is important that, as integral parts of their sustainable development plans, countries in the MENA region continually demonstrate their ability to transform, recognizing the need to address gender inequality.

\subsection{Theme Five - Partnership for Development (Goal 17)}

The 2030 Agenda for sustainable development requires efforts in several

27 Organisation for Economic Co-operation and Development (OECD), MENAOECD Governance Programme, Women in Public Life: Gender, Law and Policy in the Middle East and North Africa https://www.oecd.org/mena/governance/ women-in-public-life-mena-brochure.pdf. World Bank, Gender and Development in the Middle East and North Africa: Women in the Public Sphere (Washington DC, World Bank, 2014).

28 Ibid.

29 Government of Egypt (n. 10). 
fronts and from all sectors of society. Moving towards universal human development requires governments, private sector and civil society working together to address the several dimensions of the Sustainable Development Goals (SDGs), at national, regional and global levels.

The multifaceted partnership framework, illustrated below highlights how every sector of society could effectively work together to achieve the 17 Sustainable Development Goals.

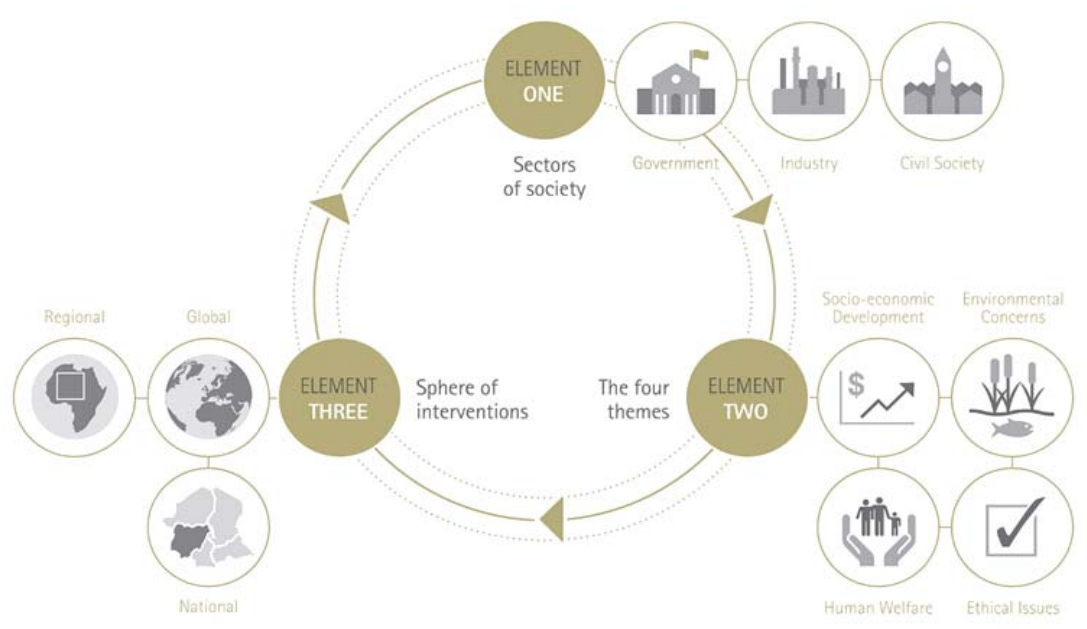

Source: Author.

Iraq is one of the countries in MENA where the need for international assistance and cooperation, is profound. After several turbulent years, the country has experienced a promising start to the vision of embracing a new social contract between the state and its citizens to enhance trust and provide opportunities for self-development, work and generation of income. Iraq considers SDGs as providing an appropriate roadmap to unify national efforts, by government institutions, private sector, NGOs and educational institutions, as well as international organizations that have supported the country during the dark periods of its history.

As a middle-income country, Egypt also recognizes that it requires assistance from the international community, both financial and technical, to implement its sustainable development agenda. To maximize resources, the country supports a responsibility-sharing approach between all stakeholders, including the private sector and development partners. 
The very rich countries in the MENA region are drawing on the benefits accruing from their energy resources to cooperate with the international community to tackle economic and social hardships faced by developing countries. Resource-rich countries in the region are indeed stepping up their international cooperation and engagement activities, and extending much needed partnership and support to countries that are less endowed with natural resources. For example, the development assistance provided voluntarily by Qatar (government and nongovernment) to other nations, increased from QR 1.6 billion in 2008 to around QR 7.7 billion in $2014 .{ }^{30}$ Also, during the 2012-2017 period, Saudi assistance saw a considerable increase of up to US\$ 38.24 billion, equivalent to 1.9 per cent of Saudi Arabia's GNI, ranking 4th among the largest donor countries, after the USA, UK and Germany. In terms of development assistance as a share of GNI, Saudi Arabia topped the list of countries in 2014, having exceeded the UN target of 0.7 per cent of GNI. ${ }^{31}$

SDG 17 clearly recognizes the importance of partnerships by all key sectors to achieve and deliver the SDGs. The next section evaluates the roles of extractive industries, especially in the energy significant MENA region, in advancing the SDGs.

\section{THE ROLE OF THE EXTRACTIVE INDUSTRY IN ADVANCING THE SDGS}

The private sector, particularly the energy industry, has played a crucial role in industrialization since the beginning of the last century. The sector has been the backbone of economic development for many resourcerich developing countries and this will continue far into the future. ${ }^{32}$ However, the sector and all companies and business organizations linked to it in some form, will need to continue to adapt rapidly to an everchanging business climate, characterized by increasing concerns for the environmental and social impacts of economic development. ${ }^{33}$ Extraction

30 Ministry of Development Planning and Statistics, Qatar Economic Outlook 20162018, https://www.arabdevelopmentportal.com/sites/default/files/ publication/944.qatar_economic_outlook_0.pdf

31 See Olawuyi (n.12).

32 WEF and IHS CERA, Energy for Economic Growth - Energy Vision Update 2012, (World Economic Forum, 2012).

33 Damilola Olawuyi, Extractives Industry Law in Africa (Springer, 2018), 1-25. 
of natural resources continually faces the pressure to demonstrate that the finiteness of the natural resources that are being extracted transcends the strata of global socio-economic development of many generations, through the value-added by such extraction and the impact of advances in knowledge and technology.

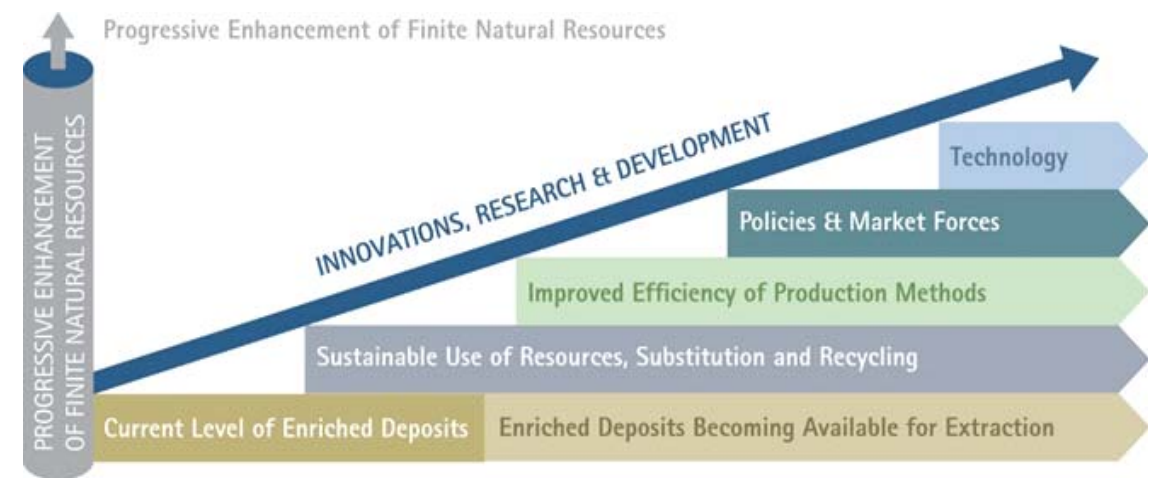

Source: Author.

The role and contributions of the extractive industry to sustainable development are embodied in an approach that realizes the opportunities for shared value creation with multifaceted benefits. It is against this backdrop that responsible companies pay greater attention to creating economic value in a manner that also creates benefits for the wider society without causing irreparable damage to the environment. For instance, it is very important for the extractive industry and related businesses operating in resource-rich developing countries to ensure that the extraction of finite, non-renewable natural resources, such as oil and gas, add value across the strata of global socio-economic development and provide opportunities for many advances in knowledge and technology in a sustained manner. ${ }^{34}$ The extractive industry sector should draw on the ability to convert natural resources capital into new forms of capital, such as economic, social and human capital, all of which provide broader focus on human conditions and quality of life issues that are essential requirements for attaining the UN SDGs. ${ }^{35}$

34 Ibid.

35 Andrew (n.20). 
The extractive industries in the MENA region can contribute their experience, technologies and resources to the implementation and attainment of the SDGs in the MENA region. However, a number of practical challenges that stifle the contributions of the private sector to sustainability goals will have to be carefully addressed. The next section examines key challenges that will need to be addressed to enhance the potential contributions of extractive sector stakeholders to the attainment of SDGs in the MENA region.

\section{KEY CHALLENGES}

Access to energy is recognized as the key that will help the world unlock the UN Sustainable Development Goals. Energy is the lifeblood of the global economy - a crucial input to nearly all of the goods and services of the modern world (WEF, 2016). ${ }^{36}$ The abundance of energy resources, particularly oil and gas, makes the MENA region well positioned to maximize the economic benefits of these resources, and to contribute to global economic growth. Fossil fuels from the MENA region have transformed the world's economy and improved the lives of billions of people. ${ }^{37}$ However, the sector needs to adapt rapidly to a changing business climate, characterized by a plethora of challenges. The ability of resource-rich countries to capitalize on their resource endowments depends on their capacity to transform, diversify and innovate, while addressing interwoven challenges. Some of the key challenges facing the energy sector are highlighted below:

\subsection{Environmental Challenges}

The world unsearchable appetite for energy leads to all sorts of paradoxes. While global energy demand continues to grow (a growth of 2.9 per cent between 2017-2018, being the fastest since the 1960s), energy sector remains the dominant contributor to climate change, accounting for 60 per cent of total global GHG emissions. ${ }^{38}$ The negative impacts of energy development, production and utilization on air, land and human health

36 World Economic Forum (WEF), Future of Oil \& Gas (WEF, 2016).

37 Audrey (n.1).

38 BP (n.6), also ExxonMobil Corporation, Outlook for Energy: A view to 2040 (Texas, ExxonMobil, 2018). 
constitute the major drawback to the energy industry's contribution to sustainable development. The extractive industry, in particular, is obligated to apply best practice to address these impacts on biodiversity and the ecosystem.

Significant progress has been made in recent years by the extractive industry, in good operational practices and advances in responsible environmental management. However, there are still areas that require continued attention in order for the sector to enhance its image and establish good environmental credentials. Some of the challenging areas include:

i. Weak environmental legislation or lack of enforcement - While most countries have environmental legislation and regulations for resource extraction, these regulations are often not enforced. The impacts associated with the sector, such as, environmental degradation; land, water and air pollution; accidents; and spills, are highly visible and have potentially far reaching consequences. This requires energy companies to not only settle for meeting the minimum requirement of the law, but proactively adopt a self-regulatory approach that goes beyond legal requirements, especially in developing countries, like the MENA region, where environmental requirements may be weak. ${ }^{39}$

ii. Increasing advocacy - The extractive industry does not have the luxury that most other industry sectors have, when it comes to location. Companies involved in resource extraction are located where the resources are found, and very often other interests, such as protection of sensitive environments, national parks or indigenous people, become competing priorities. This calls for more robust decision-making processes that could increase the cost of doing business. ${ }^{40}$

39 Damilola Olawuyi, "Energy Poverty in the Middle East and North African (MENA) Region: Divergent Tales and Future Prospects", in Inigo Del Guayo, Lee Godden, Donald N. Zillman, Milton Fernando Montoya, \& Jose Juan Gonzalez (eds.), Energy Law and Energy Justice (Oxford University Press, 2020) 254-272.

40 Ibid. See also Damilola Olawuyi, "Can MENA Extractive Industries Support the Global Energy Transition? Current Opportunities and Future Directions" (2020) Extractive Industry and Society Journal (Elsevier, London) https:// doi.org/10.1016/j.exis.2020.02.003. 
iii. Internalizing all externalities - There is a common perception that energy companies are not fully internalizing all costs resulting from environmental responsibilities and obligations. The major challenge here is the lack of appropriate methodologies for assessing the costs associated with various environmental impact. For example, industries, including energy companies, are still grappling with an acceptable price on carbon, in order to be able to determine the true costs mitigating their carbon footprint.

iv. Slow pace of multilateral environmental processes - The multilateral processes involved in the negation of environmental treaties and international agreements are often painstakingly slow. This leads to lack of clarity for multinational companies, in particular, that are required to take quick business decisions. Prompt investment decisions, based on assessment of expected liabilities, are hallmark of business enterprises that are required to conduct their activities in a manner contributing to the wider goal of sustainable development, within the framework of the laws in the countries in which they operate, and in consideration of relevant international agreements. When the process for formulating the required information is slow and protracted, investment flow into critical sectors, such as oil and gas, particularly in developing countries, is seriously hampered.

v. The need for a precautionary approach - The precautionary approach involves the systematic application of risk assessment, risk management and risk communication. When there is reasonable suspicion of harm, decision-makers need to apply precaution and consider the degree of uncertainty that appears from scientific evaluation. The data and information required to unlock the key to a precautionary approach, from a business perspective, are often lacking. Some companies struggle to support the precautionary approach because the business environment in most developing countries does not show that it is more cost-effective to take early action to prevent environmental damage than to fix it.

\subsection{Geopolitical and Socio-Economic Challenges}

The broad geopolitical and socio-economic category is comprised of many challenges, ranging from population growth, business ethics, volatility 
of commodity prices, energy subsidies, conflicts, security of supply, etc. ${ }^{41}$

In broad terms, the impact of regional conflicts and geopolitical situations in resource-rich countries, such as in the MENA region, affect the private sector in several ways. ${ }^{42}$ Regional conflicts paint a grim future of the region, where investment could be seen as very challenging. While it may be certain that the world cannot afford to have failing states in the MENA region, conflictual situations still make it difficult for the private sector to make long-term commitment to invest. The extractive industry is capital intensive and required long lead time to mature. Secondly, the private sector is often tainted with the broad-brush of uneven distribution of benefits accruing from natural resources. The record of managing natural resource wealth to promote economic development is mixed. ${ }^{43}$ While some countries in the MENA region have done so with great success, others continue to record growing income inequalities, despite their endowments of huge natural resources. Communities, especially around where energy company operations are based, expect the private sector to provide services that are supposed to be the traditional responsibilities of the state or local authorities. The private sector is increasingly finding that they are expected to do more than simply paying prescribed taxes to the state, especially in jurisdictions, where poor management of government revenue is endemic. In addition, the private sector is often caught in between the government and the communities during incidences of social upheavals or unrest that are directly attributed to poor management of the fiscal rents generated from the development of natural resources. Communities, particularly those near where the resources are located, have the expectation and mind-set of the government providing every benefit to its citizens, especially during times of boom. When low commodity prices impact negative on cash flow to government revenue, and social expectations could not be met, communities often turn their attentions on the private sector, seen as easy target to vent their frustrations. Also, sustainable social and economic development of communities requires the cooperation and collective efforts of several actors. In pursuit of sustainable development objectives, private companies are expected to be more proactive and committed to structured and well-funded partnerships with government,

41 WEF (n.35); Andrew (n.20); World Bank (n. 23).

42 Olawuyi (n.38).

43 WEF and IHS CERA (n.31). 
NGOs, CBOs, educational institutions and other developmental agencies in the task of social and economic upliftment of the communities around their operations. In addition to environmental impact assessment, it is now common practice to conduct a social impact study for any proposed major project prior to commencement, whether this is a regulatory requirement or not.

\subsection{Changing Policy Landscape}

As countries, particularly developing countries, experience growth in transportation, power generation, and industrialization, energy requirements will largely continue to be powered by oil and gas. The very large energy consumers like the USA, China, Japan, and others, would continue to rely on all sources of energy as part of their sustainable development strategies. ${ }^{44}$ However, new policies are constantly evolving in these countries, as part of efforts to address challenges, such as, security of supply, climate change and air pollution.

Furthermore, a great deal of new and innovative techniques and ideas are being implemented globally, as the pursuit of green energy gains momentum. Many countries have developed policy initiatives to spur demand for renewable energy. The rationale for renewables includes the need for energy that is secure, reliable, improves public health, protects the environment, addresses climate change, creates jobs, and provides opportunities to demonstrate technological leadership.

The pace and scope of changing policy landscape, driven by the need to transform the energy sector, have the potential to impact on the role and contribution of the extractive industry to the economies of all countries in the MENA region. The policy framework for ensuring successful and profitable exploitation of natural resources are increasingly becoming wider in scope, compared to aspects of macroeconomic and social policies of the past.

The private sector does not only need to proactively engage in policy development, it should be in the forefront of promoting pragmatic business-friendly policies. This requires concerted efforts by the private sector to lead by example through the adoption of well-defined set of policies that show visible and demonstrable commitment by the top management of the organization. The policies should be publicly available and regularly communicated to employees and stakeholders, ensure the

44 Ibid. 
active involvement and participation of all employees at all levels in the implementation.

The process of policy formulation and revision could be complex, adversarial, unconstructive, and involving structured and unstructured groups of stakeholders with diverse socio-economic interests and agendas. Energy companies that are not skilled or well-resourced to handle such consultative process, could find themselves exposed to reputational risks at local, national, regional, and international levels.

\subsection{Scaled Involvement of the Private Sector}

The challenge associated with the need to scale up the involvement and participation of the private sector, particularly in the context of the MENA region, is considered in two main aspects - opening up National Oil Companies (NOCs) for private investment, and increasing investment in non-traditional energy sources.

The special report by UN Intergovernmental Panel on Climate Change (IPCC), released in October 2018, affirms that massive transformation of the energy sector is required to respond adequately to the threat of climate change. The IPCC estimates that an average investment of US $\$ 3$ trillion a year would be needed in the next 30 years to transform the world energy systems, in order to meet the goal of the Paris Climate Change Agreement. It is expected that much of the investment will involve shifting money from fossil fuel systems. It projects that on a $1.5^{\circ} \mathrm{C}$ pathway, clean energy investments would overtake fossil fuel investments by about 2025, and all investments in coal that lack carbon capture and storage technology would be halted by around $2030 .{ }^{45}$

Investments in renewables by traditional energy companies, as well as, major energy consuming nations, have been growing in recent years, reaching a comparable milestone in 2015 , when renewable power technologies for the first time attracted more finance than non-renewable power technologies. In 2017, for example, China invested a record US $\$ 126.6$ billion in renewables, up 31 per cent as compared to $2016 .{ }^{46}$ There were also sharp increases in investment in Australia (up 147 per

45 UN Intergovernmental Panel on Climate Change (IPCC), IPCC Special Report on the impacts of global warming of $1.5^{\circ} \mathrm{C}$ above pre-industrial levels and related global greenhouse gas emission pathways (Geneva, IPCC, 2018).

46 UN Environment (UNEP) and Bloomberg New Energy Finance, The Global Trends in Renewable Energy Investment (Nairobi, UNEP, 2018). 
cent to US\$ 8.5 billion), Mexico (up 810 per cent to US\$6 billion), and Sweden (up 127 per cent to US\$3.7 billion). A total of 19 countries invested more than US $\$ 2$ billion each, in renewables. Major oil and gas companies are increasing their exposure to renewables and other clean technologies. The spending, so far at just US\$6 billion in four years, is still a tiny fraction of investment in the core business, as companies are still trying to assess technologies and timing to find where they can create value. The trend is expected to grow in time as companies move from the formative stages of positioning and testing into full-blown merger and acquisition (M\&A). Both Total and Shell, for example, are planning to invest up to US $\$ 2$ billion a year, with Total committing to having 20 per cent of assets in renewables by 2030 .

Notwithstanding the significant contribution made so far by traditional energy companies in the MENA region, substantial amounts of investments are still required to bring the region's massive reserves of natural resources to the market. To materialize these investments and attract suitable investors, a flexible and competitive legal and fiscal framework need to be put in place. Therefore, the selling of shares in NOCs, albeit a minority stake, is a step in the right direction that will provide the needed extra cash to revive, sustain or increase investment in the oil sector. This process is, however, complex and challenging, involving much scrutiny and transparency. To get a fair valuation, the NOCs are obligated to disclose to potential investors, some sensitive information relating to their balance sheet, structure, and business strategies that they would have otherwise protected as proprietary information for competitive advantage.

\subsection{Diversification of the Economy}

The countries of the MENA region are not immune from the increasing need of nations worldwide to diversify their economies. Considering that much of the economies of most countries in the region are based on the energy sector, the high volatility of commodity prices underscores the importance of economic diversification. Many countries in the region are striving to maximize the benefits from their resource endowments by encouraging the growth of related industries. ${ }^{47}$ The new industries could be in direct competition with traditional energy companies, but they

47 Olawuyi (n. 39), see also WEF \& IHS CERA (n.31). 
could also be great opportunities for expanding their knowledge and business expertise. The technologies, knowledge and expertise required to embark on a successful process of diversification of the economy, often reside in the private sector. However, most of these technologies are considered proprietary assets that are jealously guarded for competitive advantage rather than viewed as resources that should be willingly shared for the common good.

In order to achieve economic diversification at the scale commensurate with current dominance of the energy sector, the goods and services from the new related industries must get to markets that are well beyond the borders of the MENA region. Although several countries, especially the GCC countries, have built a strong foundation, on which economic transformation can flourish, there are opportunities for the private sector to contribute to improving the airports, harbours, and other transportation infrastructure, to support trade and commerce.

Some countries within the region, are successfully navigating the intricate maze of transitioning to clean economic growth, pointing to the fact that the above challenges could be turned into opportunities for transforming the economy of the MENA region. ${ }^{48}$

\section{PROMOTING SUSTAINABILITY IN EXTRACTIVE OPERATIONS: RECOMMENDATIONS}

Heavy reliance on oil makes the economies of the countries in the MENA region highly sensitive to international circumstances, which in turn affects their strategy for mobilizing financial resources for SDGs related investments, among many competing priorities in national budgets. The extractive industry can play an active role in promoting sustainability in the MENA region, but it has to be resolute in addressing the plethora of challenges facing the sector through a slow painstaking process requiring perseverance and determination. ${ }^{49}$

The limited sample of all the efforts being exerted to place the countries in the MENA region on the path to sustainable development shows that the region has a lot of untapped potential. It is clear that, with its abundance of natural resources and active participation of the

481 Audrey (n.1).

49 Andrew (n. 20). 
energy companies, the region is capable of achieving the transformative goals of the 2030 Agenda.

There is a need for redoubling of efforts by all stakeholders involved in the energy sector to collaborate in ongoing initiatives aimed at transforming and diversifying the economy of the MENA Region. In particular, and in the context of the 17 UNSDGs, energy companies could contribute by ensuring that they make the development of the countries where they operate as one of their core business objectives. Similarly, there is a need for companies to ensure that their interests are aligned and consistent with the priorities set by the countries in their 2030 development agendas (the respective Vision 2030s).

All countries in the MENA region are signatories to several UN treaties that highlight key environmental obligations and aspects that require attention and concerted efforts by the private sector. The Paris Agreement, for example, requires each country to set forth a climate action plan (a Nationally Determined Contribution - NDC), which describes the targets of the country, and the means for reaching the targets. These NDCs should provide clarity to the energy sector on, the impact of new climate policies, the expectations of governments and the role the energy sector is expected to play in the global effort to combat climate change.

Other areas in which the energy sector, particularly in the MENA region, could help promote sustainable development, include in the development of technology. Energy companies should ensure that their activities are compatible with the science and technology (S\&T) policies and plans of the countries in which they operate and, as appropriate, contribute to the development of local and national innovative capacity. They should adopt, where practicable in the course of their business activities, practices that permit the transfer and rapid diffusion of technologies and know-how, with due regard to the protection of intellectual property rights. Similarly, where relevant to commercial objectives, energy companies should develop ties with local universities and public research institutions and participate in cooperative research projects with local industry or industry associations. They should allocate funds for supporting the R\&D efforts and initiatives undertaken by local universities. Such funds should be earmarked for research and ring-fenced from other core business activities. Furthermore, energy companies should use their business expertise, experience and insights to assist in unlocking the potential of untapped assets within the region, such as, renewable energy sources. 


\section{CONCLUSION}

The development of the energy sector, in general and the operations of oil and gas industries, in particular, have potential impacts on a range of areas covered by the SDGs. Energy is the golden thread that connects economic growth, increases social equity and creates an environment that allows the world to thrive. It is a key driver on which the other SDGs hinge and sustainable development is not possible without sustainable energy.

Nobody understands what it would take to transform the energy sector more than the players within the sector. Therefore, the energy industry should continue to step forward to be counted among the leading actors in global drive to address environmental challenges. The SDGs, that include a dedicated stand-alone goal on energy, serve as a good blueprint for framing the corporate social responsibility (CSR) of companies wishing to capitalize on the positive benefits to society, while mitigating, in a meaningful way, the adverse impacts of their activities. 